\title{
Unique Experiences with Intercontinental Trials in Stroke - Part II
}

\author{
H.J.M. Barnett, John (Jack) Coleman Laidlaw
}

\begin{abstract}
Supported by the Canadian Medical Research Council we performed a randomized trial extending from Newfoundland to British Columbia. With others a number of observations showed that aspirin will reduce stroke. With National Institute of Neurological Disorders and Stroke support we learned who would benefit and not from surgery in these stroke threatened carotid diseased patients. We evaluated the upper limits of acceptability of complications beyond which harm was done. Amassing this large data base of approximately 5000 individuals, followed for five years, previously unknown carotid phenomena were observed: 1 . Ischemic stroke occurs in patients with prolapsing mitral valves; 2 . There is risk of stroke in patients with residual thrombi in the occluded stump of the carotid artery; 3. We detected a lower risk than expected in patients with nearly occluded carotid arteries. We support the contention of Yusuf and Cairns' that Canada needs to give more financial support to purely clinical research. It pays off !
\end{abstract}

RÉSUMÉ: Expériences uniques acquises au cours du Intercontinental Trials in Stroke - 2e partie. Avec le soutien du Conseil de la recherche médicale du Canada, nous avons effectué un essai randomisé pancanadien, qui a eu lieu de Terre-Neuve à la Colombie-Britannique. Un certain nombre d'observations ont montré que l'aspirine diminue les accidents vasculaires cérébraux. Avec le soutien du NINDS, nous avons appris qui peut bénéficier d'une chirurgie parmi les patients avec maladie carotidienne à risque d'un accident vasculaire cérébral. Nous avons évalué les limites supérieures d'acceptabilité de complications au-delà desquelles il y a risque de causer un préjudice. La base de données, incluant les données recueillies chez 5000 individus qui ont été suivis pendant cinq ans, a permis de faire des observations inédites : 1. L'accident vasculaire cérébral ischémique survient chez des patients porteurs d'un prolapsus mitral ; 2. Il existe un risque d'AVC chez les patients porteurs d'un thrombus résiduel dans le moignon d'une artère carotide occluse ; 3 . Nous avons détecté un risque plus faible qu'attendu chez les patients qui avaient des artères carotides presque occluses. Nous nous joignons à Yusuf et à Cairns pour affirmer que le Canada devrait offrir un soutien financier accru à la recherche clinique pure. Ça en vaut la peine!

Can J Neurol Sci. 2013; 40: 645-651

North America and Europe have made serious inroads towards defeating vascular disease. Canadian and especially Ontario and Calgary centres have been involved in making fundamental reorganization of personnel and clinical observations. The clinical results are on record and need not be repeated. ${ }^{1,2}$ The methodology particularly in the extension of muticentre trials to intercontinental and cross-cultural trials is the motive behind this communication. In Part I, (Experiences with the Execution of Intercultural, Intercontinental Trials) ${ }^{1}$ the basic principles for conducting and reporting these trials undertaken by the one of the authors are outlined. As Yusuf and Cairns have pointed out in a recent paper $^{3}$ in The Journal of the Canadian Medical Consortium, support of clinical trials is deplorable even for important illnesses. This compares badly with one of the author's better experience in finding funds for vital issues in competitive grants from the American National Institute of Neurological Disorders and Stroke (NINDS).

The disturbing finding that stroke and heart attack remain listed high among the common causes of death in spite of legitimate claims of great strides and substantial advances achieved is probably best explained in both men and women because they are living beyond our expectations of a decade or more ago. They remain serious challenges. It is premature to hang out the banner of "Victory Achieved". Because of the arrival of, and compelling demand for, Evidence-Based Medicine, dependent most commonly on Randomized
Controlled Trials, research-oriented stroke neurologists and cardiologists must remain in the trenches and may carry only the banner "Soldiers and Veterans of the Vascular Disease War". Truce is not yet a reasonable proposition.

We can start Ontario's first battle in the fight against stroke by describing insulin, a Toronto triumph. Two patients going into hyperglycemic acidotic coma constitute the sample size of a trial to prove its efficacy beyond doubt. Prior to that recovery from diabetic coma was practically an unknown outcome. Today we are not likely to encounter diabetic coma. Nevertheless unrecognized and uncontrolled or poorly controlled diabetics are prone to early heart attacks and premature strokes, both due to atheroma. Given constant good control as the patient ages, there is sufficiently substantial reduction in the diseases caused by atheroma as to oblige physicians to counsel their patients towards prudence and diligence to maintain effective glycemic control. Gone forever are feasts on bon-bons, icing on cake, potato and corn feasts. Joslin, the Boston diabetes guru, pointed out in a Toronto lecture that diabetics should be strict about their

From the University of Toronto, Toronto, Ontario, Canada.

Received March 1, 2013. Final Revisions Submitted April 5, 2013. Correspondence to: Henry J.M. Barnett, Suite 701, 305 Balliol Street, Toronto, Ontario, M4S 3H5, Canada. Email: hjmb@bell.net 
diet at every meal and throughout each day with two exceptions: their birthday and the day of their particular religious holiday feast.

Randomized, but well-controlled trials are of particular importance in conditions with variable outcome such as are found with much vascular disease, just as they are with most cancers, epilepsy, polio and multiple sclerosis to name a few. David Sackett, Fraser Mustard, Brian Haynes, Jack Hirsh and Michael Gent played key roles in developing Canada's first major Department of Epidemiology Methodology and Biostatistics at McMaster University. Even in trials dealing with common disorders it became apparent that one exceptionally large city centre and at times centres across countries and continents were needed to produce sufficient numbers of outcome events in afflicted patients to provide early significant answers. Thus multi-continent trials were born. Compared to single centre studies they provided different but more demanding issues in trial execution needing particular education for the investigators about all required aspects of the described but unique protocols. Most strict attention to the principles defined as essential in our past communication need total attention. ${ }^{1} \mathrm{~A}$ team of knowledgeable and committed investigating assistants must be recruited at the Central Office. Ready communications with the investigating centres is vital so that all their questions can be answered and all their timely reports received and reviewed.

That remarkable research project, the Framingham Study, coupled with the Oxfordshire Community Study, ${ }^{4}$ observations from the negative Trial of Org. 10172 in Acute Stroke Treatment (TOAST) trial ${ }^{5}$ run by Harold Adams and to records made and followed for the 11 years of the North American Symptomatic Carotid Endarterectomy Trial (NASCET) all found that the risk profile for stroke was very similar to the risks facing subjects with coronary artery disease. Uncontrolled hyper-tension, diabetes mellitus and tobacco use were the major villains. David Spence has made several pertinent observations on high blood pressure. ${ }^{6}$ Fat arms need a special cuff or will show a misleadingly high reading. "White coats" commonly but artificially drive up blood pressure and require a calm break before a second reading. High blood pressure (BP) despite best therapy may require a search for renal artery stenosis, now simplified by computed tomogram (CT) or magnetic resonance (MR) angiography.

Fraser Mustard's work in Toronto on platelets and his discovery that two drugs, aspirin and sulfinpyrazone, known to be safe for human consumption, both altered the thrombogenic properties of the blood platelets. Mustard declared that it was time for a randomized trial that would test both drugs in a factorial design against placebo. This led to Canada's first large inter-provincial (Newfoundland to British Columbia) trial. With a protocol designed by Sackett, Hirsh, Gent and Barnett such a trial was prepared. ${ }^{7}$ It was funded by the Canadian Medical Research Council for the modest sum of $\$ 750,000$ over two-anda-half years. No salaries or travel expenses were paid, no payments were made to investigators for entering and following the patients. Much of the Grant money was spent in checking the ongoing aggregability of patient's platelets as a check on compliance. The physiological mechanism of anti-thrombotic action of aspirin was as yet not known but its anti-platelet effect was well studied. Barnett was invited to lead the plateletinhibiting drug trial, including the recruitment of the centres, and a vigorous Central Office team. All were urged to take all precautions to avoid patient drop-out and assess strict compliance in the use of study medications. In the pre-electronic age the communications were by phone and later-on by facsimile. Platelet aggregation, the beginning of thrombus formation, was inhibited.

The ocular transient ischaemic attacks (TIAs) described by Miller Fisher, Ralph Ross Russell and many others were eliminated. There were ten Canadian centres from the Atlantic to the Pacific that entered their patients, some with hesitation, as the concept of a placebo was novel to most physicians in those early days. This was the first multicentre randomized trial involving patients threatening with stroke. Propeller-driven airplanes and regular mail service were our methods of datagathering including transmitting original $\mathrm{x}$-rays and study forms. Digitized images were still ahead. Problems seen by the study central office staff were discussed by mail or telephone with the investigators. The principal investigator (PI) screened all outcome events and checked their appropriateness, completeness and acceptability before sending them to the computer staff where they were held in secret. The study computer was huge in the early days, filling a room, at first a small outpatient room in University Hospital and later in the Robarts Research Institute. Statistical analysis confirmed the pilot observation that aspirin reduces stroke occurrence in TIA patients. ${ }^{7}$ (Figure 1)

Much travel was required of the PI to sustain enthusiasm for the Trial. Despite the distances between centres, the concept of a multi-centre trial extending from Newfoundland to Victoria, BC, proved to be workable with minimal loss to follow-up.

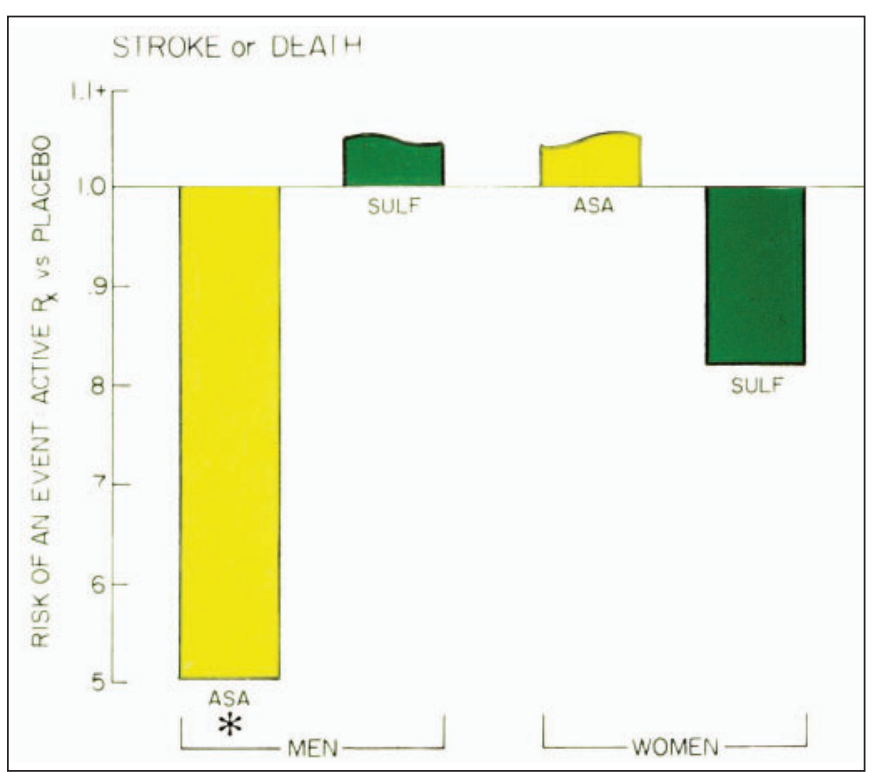

Figure 1: Bar-graph illustrating risk of stroke or death in men in aspirincontaining arms of Canadian aspirin study favoring males. The asterisk represents (post hoc analysis) apparent significant benefit for higher-risk men and none for the inadequate numbers of lower-risk women. Subsequent larger studies found benefit for women. 
Enthusiastic Canadian centres soon had 585 patients with ocular and hemisphere TIAs in the trial. We found benefit for patients taking aspirin but not sulfinpyrazone. The only subgroup for analysis described in advance was the degree of carotid or middle cerebral artery stenosis. The risk for the recruits and the benefit from aspirin increased with the increase of stenosis. We did not pre-describe gender as a special sub-group but took the liberty of reporting that we found benefit only in males. This unannounced report of specific gender benefit properly distressed many critics of our reporting including Lilienfeld and Kurtske. ${ }^{8}$ We did in fact violate one of the cardinal principles that are properly required in randomized trials. Eventually our findings were explained: The explanation for our lack of finding of benefit in our women was shown to be due to the fact that we had too few females in the trial; women presenting with TIA were eventually shown to be at lower risk than males. We should have had more women in our trial instead of more men. Later trials eventually proved that there was benefit, albeit less pronounced, for women. Later trials soon also corroborated the benefit of aspirin in stroke prevention, notably the Bousser trial ${ }^{9}$ in Paris and the UK trial in Oxford ${ }^{10}$ supervised by Warlow.

Other platelet inhibitors have come along, none significantly better than aspirin. Clopidogrel (later called Plavix) was the only one widely promoted and at times I fancied it was prescribed because to use the alternative sounded too trivial: to send a patient away to "take aspirin" for something as formidable as a possible paralyzing stroke. ${ }^{11}$ Clopidogrel is vastly more expensive by as much as $60 \mathrm{X}$ more than aspirin. Giving it with aspirin it is even to be regarded as a mistake as the combination gives rise to too many brain hemorrhages. The CAPRIE trial was the singular trial of this new compound against aspirin. In the trial there was an arm of "stroke patients" and a similar separate number with "peripheral vascular disease" and a third separate arm of patients with "recent myocardial infarction" (6300 in each arm). In reporting this trial they violated two fundamental principles of randomized trials. They would not share with some of us, including several other stroke neurologists, who requested more details post- publication about the stroke group. Secondly and most shockingly they did not publish any pre-publication Methods Paper setting down clearly their plans for the unique analysis that they performed. It had to come as a complete surprise that for their key analysis they added up all outcome events in all three arms against aspirin and behold this combined outcome analysis favored Clopidogrel (now to be marketed as Plavix) for all vascular disease including mirabile dictu stroke. Separate analysis of the original peripheral vascular disease (PVD) group was the most positive, in the MI group aspirin was decidedly more effective, in the stroke group there was nonsignificant benefit of Plavix over aspirin. Despite lavish promotion of Plavix, aspirin remains standard therapy worldwide for TIAs and strokes.

In the USA and Europe anticoagulants in the form of warfarin were shown in several separate randomized trials to reduce very significantly the likelihood of stroke when individuals of either gender developed atrial fibrillation (AF). Wisely this recommendation has been widely accepted. Heparin is now uncommonly used for stroke or stroke-threatened patients. This is fortunate as it carries a higher risk than warfarin. Warfarin, if tolerated, is now standard treatment for continuing or intermittent AF and other processes causing cardiogenic stroke resulting from red thrombi as opposed to the white thrombi of platelet induced white thrombosis.

The success of what became known as the "Canadian Aspirin Study" led NINDS to alert the community of stroke investigators that they wished to verify by random trial the claims made by those performing the delicate procedure of superficial temporal (scalp) artery to a branch of the middle cerebral artery whose normal blood flow was impaired or occluded by plaque(s) of atheroma and that good clinical results would follow. Their search led them to seek a trial to prove or disprove the value of cerebral by-pass surgery. It was claimed by the enthusiasts in Rochester Minnesota, also in Detroit, Michigan, in Naples, Italy and in Los Angeles, California that strokes were prevented and the impaired brain function was restored by this by-pass. National Institute of Neurological Disorders and Stroke offered a grant if a proposal was produced and acceptable to their review committee. What was called for was a protocol describing the modus operandi of such a study and the selection of a team of expert stroke neurologists, vascular radiologists and surgeons with proven skill at the painstaking and delicate procedure and prepared to have appropriate patients willing to accept randomization to the operation or to the control group both to receive best medical care. Between our team and our colleagues at McMaster, particularly led by Sackett, Haynes and Taylor, we were successful in the competition and another multi-centre stroke prevention trial was launched. With help from the Director of NINDS Murray Goldstein, we traveled together to recruit world-wide centres when we learned that the appropriate surgical skill and expressed dedication to modern scientific scrutiny and data-gathering were present. We ended up with 77 centres on five continents and eventually a total budget of nine million dollars. We were able to establish that the operation did not reduce subsequent strokes, nor did it allow a return of brain or ocular function in a significant fashion. ${ }^{12}$ Several subsequent attempts have been made to find otherwise, one in Japan and one centered in St. Louis recruiting patients who were shown by PET Scanning to have defective hemodynamics related to cerebral artery lesions, but all without success. When the Federal Drug Administration, Veteran's Affairs and Blue Cross recommended against payment for the by-pass procedure for threatening or developed cerebral or ocular ischemia it became almost a relict procedure for cerebral artery ischemic lesions. The results of our study saved Health Care systems millions of dollars annually compounded forever. The NINDS used our results when asking for Grant renewal to the appropriate Senate Committee. As they could prove "Expensive research coming from a base of sound evidence can save public money". At the moment this appears to be better understood by American than by Canadian granting agencies as witnessed by Yusuf and Cairns. ${ }^{3}$

Heparin ${ }^{13}$ was a discovery at Johns Hopkins but it remained for Charles Best in his lab on College Street in Toronto to produce an acceptable formulation of heparin allowing of its human use in such as preventive therapy for pulmonary embolism in the presence of crural or pelvic phlebitis (common with hip operations, pregnancy and lengthy confinements to bed); to allow of coronary by-pass grafting and other open-heart 
procedures; cerebral venous and venous sinus thrombosis (now readily diagnosed by MR angiography). Bigelow's experiments on the use of severe hypothermia in the heparinized ground-hog could lead to cardiac arrest if the cooling was extreme. A fragment of vicarious pleasure to us was the fact that the hibernating ground hogs were dug up in dead of winter by Bigelow's research staff, one of whom was Ross Fleming in his resident days. The digging was in my part of the Happy Valley Forest, in the middle of the Oak Ridges Moraine. They sought what proved to be a non-existent "hibernating gland". The happy result of this negative research was Bigelow's design of the first pace-maker suitable for human subjects. Its insertion is now an every-day event in cardiology units and often takes place is an outpatient procedure.

In the early days of Harvey Cushing, angiography was still ahead and the diagnosis and localization of intracerebral aneurysms and arterio-venous malformations causing subarachnoid hemorrhage and possibly intracerebral bleeding and stroke was difficult. In 1928 Moniz in Portugal introduced cerebral angiography and this scene and many others changed forever. Adventuresome surgeons such as K.G. McKenzie at the Toronto General Hospital (TGH) followed by Harry Botterell began to clip aneurysm necks and perfected this "clipping" technique. Meanwhile Richardson and Hyland, my Toronto teachers, wrote their classic paper on the pathology of berry aneurysms using Linell's copious and careful autopsy files in the Banting Institute. ${ }^{14}$ When it was available they reported relevant clinical symptoms. Still at times the tragedy is that the fatal ruptures were not heralded by symptoms linked by the patient or doctor to the lesion.

The files in the Pathology Department at the Banting Institute gave rise to two more significant vascular observations: First a patient dying of post-partum cerebral venous and venous sinus occlusion stimulated one of us to examine all related reports in Linell's post-mortem files. Our eventual manuscript, published in Brain, ${ }^{15}$ was able to eliminate much previous speculation about the cause of this rather uncommon but often neglected event. Our manuscript has been dubbed a land mark contribution. The real credit belongs to that extraordinary neuropathologist, the late Professor Eric Linell and his treasuretrove of decades of meticulous records.

The second observation developed at the post-mortem table in the Banting Institute where we were examining a large heart, the site of what is now called Hypertrophic Cardiomyopathy or sub-aortic stenosis. Wigle, an observant cardiologist watched and was as puzzled as the rest but assiduously followed it up and finally with a Boston and British colleagues described this familial entity. ${ }^{16}$ The TGH has a clinic dedicated to following 1500 patients with the condition and have been able to treat their cardiac insufficiency and rhythm disorders when they develop and have come up with surgical indications and procedures when appropriate supportive therapy fails.

Ontario's singular contribution to cerebral vascular disease from the mid-fifties to the early-eighties was the cracking of the enigma of safe surgery to deal with posterior fossa aneurysms. Until Charles Drake in London, Ontario, a true surgical master, led the way, this clipping was mostly too hazardous to attempt. He ended up defeating the problem. He spared the small arteries supplying the brain-stem and taught many eager watchers his meticulous unhurried methods often using his specially designed clip. ${ }^{17}$ Hundreds of doctors literally from all over the world flew to London with their patient to ask for his help. Other than Penfield, no Canadian medical person was such a magnet. I recall one day saying to him as we left the hospital together about 8:00 p.m.: "Charlie you look tired": His reply: "I just finished my third basilar aneurysm for the day". A record never again to be repeated.

Overlapping the time of Charlie's death from bronchogenic cancer, interventional catheter-directed neuroradiology was introduced at University Hospital by Gerard Debrun. I recall most vividly our telephone call to him and his ready acceptance as we recruited him from Paris. Among those whom he trained was Fernando Vinuela. At first few recognized the traditiondefying therapeutic time-bomb in our midst and maybe slowly recognized the major steps forward introduced by these visionaries. Detachable balloons delivered by catheter were introduced early after Debrun's arrival in Canada, and solved forever the vexed problem, for most of those affected of distressing carotid-cavernous fistulae, by a technology he had developed after visiting the secretive Serbinenko in Moscow. Debrun trained Pellz and Vinuela; the latter was lured to Los Angeles and with his Italian research fellow Guido Guglielmi developed and introduced coils eventually capable of being detached, filling the sacs of aneurysms and often provoking an occluding thrombus within the sac that would no longer bleed.

The direct attack by craniotomy on aneurysms markedly decreased at the time of Drake's demise. Some still need craniotomy because of wider than usual necks. Credit for this huge advance belongs to Debrun and Vinuela which was pushed along in London, Ontario by David Peltz and his surgical colleague Steve Lownie. This change in practice style is an excellent example of interdisciplinary activity not just in research but in practice. At University Hospital in London and at Sunnybrook and Western Hospital in Toronto, every aneurysm patient is discussed by a combination of the stroke neurologist, the neurosurgeon and the interventional radiologist before deciding on the prime therapy for the particular patient. Interdisciplinary team effort at work.

The surgical procedure next to be tackled in a multi-centre clinical trial (upward of one hundred centres on five continents). Australia was involved and as carotid stenosis is not common in Japan, this country was not involved in the evaluation by randomized trial of the commoner procedure of re-establishing carotid artery flow and removing a major source of arterial lesions capable of producing serious emboli most commonly by carotid endarterectomy. The NINDS were concerned that this procedure had been performed in the USA and Canada at least one million times and many expressed the view that we did not know which patients with symptoms due to carotid stenosis were most likely to benefit, which ones would not benefit and who might benefit in a more muted fashion. After 11 years and a budget close to 45 million (US) dollars (largely to pay for nurse or research fellow as coordinators in every centre and to pay modest sums only for completion of perfect study forms for entry, follow-up and outcome forms). This huge amount was NINDS' largest Grant to an "alien investigator" and because of the size of quarterly money transfer it required periodic approval from the US Secretary of State. The Robarts Institute, was the 
Grant-holder and Barnett the designated PI. We were able to conclude that those with symptoms related to stenosis of $\geq 70 \%$ benefit most when performed with a skill reflecting a complication rate of $\leq 6 \%$ and such patients should be advised to have endarterectomy. ${ }^{18}$ If the stenosis was $\leq 50 \%$, they might fare worse than with good medical care. Patients with symptoms related to $55-69 \%$ stenosis had benefit but only in skilled hands and with less benefit than when the narrowing was greater. The UK trial, ending as we concluded ours, reached similar conclusions for the total and for all sub-groups. ${ }^{19}$ Their imaging had been less demanding and they had to tolerate telephone follow-up. They also permitted surgeon discretion. We had different protocols.

There was considerable and important opposition from both vascular and neurosurgeons to the launch of this trial, many claiming that they knew "from personal experience" who should have carotid endarterectomy (CE). An encouraging event was reported to us from the Annual Business Meeting of the American Society of Vascular Surgeons. Two recently-trained members stood and proposed a motion of censure to the NINDS for requesting an application to perform our proposed trial. Immediately the revered, influential and experienced expert advocate of CE, Michael Debakey, stood up and asked that nobody second this motion. As he told the audience huge amounts of uncontrolled data was not scientific proof of value to decision making for therapy: "This is a timely study and we should all support it", he said. The motion was not seconded. Written attempts to dismiss the need for NASCET from the American Neurosurgical Society were equally futile but pointed to turbulent waters ahead for NASCET's investigators.

In the course of the NASCET studies, two previously unrecognized carotid phenomena of importance were described. When the carotid narrowing was so extreme (we called it nearocclusion) as to provoke the development of extensive collateral circulation ${ }^{20}$ the risk of stroke was only as much as for patients with moderate stenosis and the need for surgery less. This extremely narrowed artery may become eventually occluded with no new ischemic manifestations. Thomas Willis' predictions of 1664 or thereabouts once again proved visionary. Curiously, one of the authors of this report (HJMB), had two minor cerebral ischemic episodes a full decade ago and a few weeks apart, that were each in turn on opposite sides of the neck and shown to be related to Carotid near-occlusions. Both shortly led to complete occlusions without new symptoms. For a decade he has enjoyed normal brain function and, like tigers and other cats, his brain and vision depends on his collaterals fed by natural external carotid anastomoses.

The second new observation was that the "stump" of an occluded internal carotid artery might be the site of a thrombosis producing embolism passing up the external carotid artery, causing ischemic symptoms. ${ }^{21}$ (Figure 2). This lesion with clumped thromus in the distal part of the occluded artery prompted surgeons to remove the stump, but it proved hazardous and they are best treated with platelet inhibitors and management of their risk profile.

Coronary Bypass grafting became perfected in many advanced countries and, in three Ontario centres, became a common operation with its value assured by American randomized controlled trials. This skill was particularly

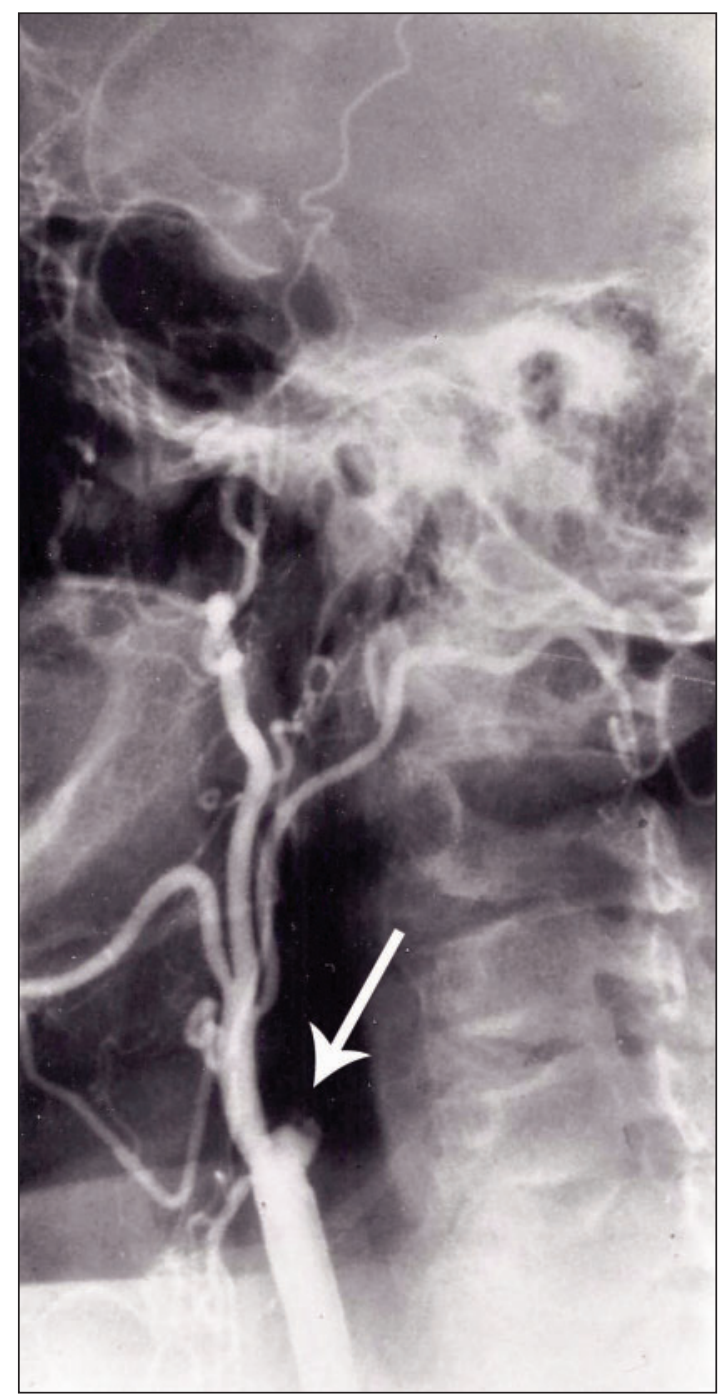

Figure 2: Illustrating an occluded internal carotid artery with a short "stump" containg thrombotic material which was found at times to embolize up the external carotid artery producing cerebral ischemia in the collaterals.

developed at the new Ottawa Heart Institute, at London's University Hospital and under the specially skilled hands of Tyrone David at Toronto General Hospital. Cardiac transplants became almost common-place.

Prolapsing mitral valve, as a reasonably rare cause of stroke, emerged from our trial data and was first described by one of us. ${ }^{22}$ Great dispute ensued but an Olmstead County survey conducted at the Mayo clinic finally was persuasive to most critics of its existence. ${ }^{23}$

For stroke, NINDS funded and to some extent managed and established without doubt that tissue plasminogen activator (tPA) given by vein within three hours of a stroke can restore or at least partially improve ischemic brain and ocular function. The task of educating ambulance drivers to rush stroke victims to stroke units spread across the country was assumed by the Canadian Stroke Network, put together under Tony Hakim in Ottawa. The 
capability spread to all provinces when provincial governments, with help from the Heart and Stroke Foundations, provided trained personnel and MR equipment to get the treatment underway. A good place to update on this subject is in a chapter by Buchan, of Oxford, in Spence's book on "Prevention of Stroke". Buchan had been influential in organizing Calgary and now the UK about the value of special "stroke units". ${ }^{24}$

"Stroke" is no longer a generic term that previously and roughly divided into those due to hemorrhage and ischemia. Stroke due to hypertensive blood vessel changes in the central periventricular part of the brain needs to be distinguished from those strokes due to hemorrhagic conversion of ischemic changes in the softened ischemic brain, also from those due to AV malformations and to aneurysms. Modern imaging methods sort them out and appropriate specific therapy may be launched. The phenomenon dubbed "Lobar Hemorrhage", mostly due to small vessel lipid changes, has been recognized largely because of modern imaging.

There is equal importance attached to recent sorting out of the specific causes of stroke carried on by the Harvard Cooperative Stroke Registry ${ }^{25}$ by the Oxfordshire Community Stroke Study ${ }^{4}$, by the TOAST Trial ${ }^{5}$ of Harold Adams and most recently from the database of the NASCET Study. ${ }^{26}$ The compelling reason for distinguishing between these causes is that all require very different management methods. The largest categories are the cardiogenic causes, followed by large-vessel disease, then by lacunes due to small-vessel disease mostly from lipohyalinosis. There are a variety of uncommon vasculopathies: Moya-Moya Disease, Takayashu's Disease and the familial chromosome abnormality (CADASIL) described by Bousser. ${ }^{27}$ Breaking down the list of stroke causes has been one of the biggest advances in the stroke field, much of it in the last two decades. Fortunately the imaging advances and chromosome studies have helped in this classification of causes which had previously been more puzzling. Their separate recognition has become an essential element in any forthcoming "stroke trials".

The day has arrived when we can list the major advances in the stroke field, many of which emanated from Ontario and Alberta: The profession a) has been educated to recognize the warning symptoms of transient ischemia; b) knows what causes of the impending stroke to seek and eliminate; c) acknowledges the importance of randomized trials to seek the needed therapeutic evidence; d) recognizes the importance and components of a stroke risk profile and know to encourage their management; e) knows what cardiac lesions are risks for stroke and the importance and the components of their medical and surgical therapy including anticoagulants and valve replacement; f) has together with the public, been educated to know that effective treatment is available if urgently sought; ${ }^{24} \mathrm{~g}$ ) has established stroke units prepared to deal with acute stroke across the country, with required imaging to help make urgent decisions; h) knows who to consider for investigation that may lead to arterial surgery and knows who should have surgery.

The Canadian Neurological Society must be given credit for alerting the original Heart Foundations of their need to embrace stroke, not only in their name but also in the rationing of their energies and funding. The Heart and Stroke Foundations in all provinces and nationally have grasped the educational nettle of stroke research as a plank in their public appeals for financial support and stroke neurologists must thank and salute them. The continuing need for rigorously supported randomized trials has recently been explored by Yusuf and Cairns. ${ }^{3}$ Canada lags woefully behind the USA and the UK in the support of clinical studies and yet much of our extended lives they believe relate to better medical practice proven of value by clinical trials. At the Robarts Institute, by a lucky spin of chance, we have benefited by trials funded by our neighbors. If Canadians are capable of answering important clinical issues we should be funding their work and not counting on the largesse of our helpful neighbors.

Embracing randomized clinical trials has been key to applying evidence-based medicine to most of these singular stroke advances. Problems remain and are in need of answers: What to do about large unruptured aortic aneurysm? This, even now, is being tackled by randomized trials and so has the ongoing problem of the unruptured berry aneurysm in the subarachnoid space or within the brain. Only such trials can expect to solve and, in time, hand our colleagues evidence-based answers and discuss with them the problems of allowable risks. The randomized trial is here to stay and, for much of vascular disease, there is no good substitute. Funding agencies need larger budgets and a greater proportion of their allocated funds needs to go to bedside and clinic studies!

A word of caution is needed here: simply designing a good trial with appropriate statistical input is only the first stage. To evaluate the robustness of the conclusions, the reader must know how meticulously the trial was executed. To check on this the reviewer must ask penetrating questions of those who wrote the manuscript. Only if all the rules for conducting and reporting a robust trial are visible can the conclusions be accepted. A lot of missing data and an excess of loss to follow-up (beyond a mere minimum) are indications of sloppy execution of a clinical study. Good trials cost the public money. The return is avoidance of disability or abandonment of public use of worthless therapy. Poor trials waste public money and may cost lives instead of pointing the way to saving them.

Systematic reviews of all published trials and meta-analyses may be in danger of including poorly executed trials. HJMB is aware of several such exercises where the methodology of trials included in the analyses were not good enough. Combining trials from others is a poor substitute for large enough, well executed trials designed in themselves to find definitive answers. Granting agencies must reflect on this.

In concluding this essay the reader must be reminded that we set out to concentrate upon the contributions to stroke reduction carried out in Canada. Putting all of them together has focused on surprising evidence of worthwhile contributions to our struggles. As Isaac Newton wisely said, in accepting the accolades of the Royal Society (and I paraphrase): "successful recent contributors stand on the shoulders of those who have gone before".

In final conclusion, this review requires further comment on the continuing importance of clinical medical science made possible by scrupulously controlled randomized trials. Without applying this methodology we would never have been certain that platelet inhibitors prevent stroke. Others were able to demonstrate their use of preventing myocardial ischemia. Additionally we have been able to determine, without equivocation who should have surgical procedures to prevent 
stroke, who is not going to benefit from surgery, who will benefit less but would be better with surgery. We have been able to be reasonably sure within what complication rates the common procedure of Carotid Endarterectomy should be offered to patients. Yusuf and Cairns have remarked on the difficulty experienced in obtaining research funds for clinical research. Granting agencies should reflect on the opportunity presented by modern methods to firmly evaluate therapy. The use of these methods will spare lives and physical dysfunction. They are expensive but not as much as stroke and heart disease burdens are to the community. We hope to see this tide of uncertainty of obtaining funds change, so that future researchers may ensure the conduct of expensive randomized controlled trials in Canadian research centres.

\section{REFERENCES}

1. Barnett HJM: Experiences with the execution of intercultural, intercontinental trials, Part I. Can J Neurol Sci. 2013;40:324-9.

2. Barnett HJM. Forty years of progress in stroke. Stroke. 2010;41: 1068-72.

3. Yusuf S, Cairns J. The perilous state of independent randomized clinical trials and related applied research in Canada. CMAJ. 2012;184(18): 1997-2002.

4. Smith CJ, Emsley HC, Libetta CM, et al. The Oxfordshire Community Stroke Project classification in the early hours of ischemic stroke and relation to infarct site and size on cranial computed tomography. J Stroke Cerebrovasc Dis. 2001 SepOct;10(5):205-9.

5. Adams, Jr, Bendixen BH, Kappelle LJ, et al. Classification of subtype of acute ischemic stroke. Definitions for use in a multicenter clinical trial. TOAST. Trial of Org 10172 in Acute Stroke Treatment. Stroke. 1993;24:35-41.

6. Spence D, Barnett HJMB. Stroke prevention, treatment and rehabilitation. McGraw-Hill Companies, Inc.; 2012.

7. The Canadian Cooperative Stroke Study Group (1978): a randomized trial of aspirin and sulfinpyrazone in threatened stroke. N Engl J Med. 1978;299:53-9.

8. Barnett HJM. Lecture at Eleventh Princeton Conference, Princeton, New Jersey, March 6, 1978. "Canadian cooperative study of platelet-suppressive drugs in transient cerebral ischemia.

9. Bousser MG, Eschwege E, Haguenau M, et al. "AICLA" controlled trial of aspirin and dipyridamole in the secondary prevention of athero-thrombotic cerebral ischemia. Stroke. 1983;14:5-14.

10. UK-TIA Study Group. The United Kingdom transient ischaemic attack (UK_TIA) aspirin trial: final results. J Neurol Neurosurg Psychiatry. 1991;54:1044-5.

11. CAPRIE Steering Committee. A randomised blinded, trial of clopidogrel versus aspirin in patients at risk of ischaemic events (CAPRIE). Lancet. 1996;348:1329-39.
12. The EC/IC Bypass Study Group. Failure of ExtracranialIntracranial arterial bypass to reduce the risk of ischemic stroke. N Eng J Med. 1985;313:891-3.

13. Bigelow WG. Mysterious Heparin, the key to open heart surgery. Scarborough, Ontario: McGraw-Hill Ryerson Limited, 1990.

14. Richardson JC, Hyland HH. Intracranial aneurysms. Medicine. Baltimore; 1941;20:1-83

15. Barnett HJM, Hyland HH. Non-infective intracranial venous thrombosis. Brain. 1953;76:36-49.

16. Wigle ED, Rakowski H, Kimball BP, Williams WG. Hypertropic cardiomyopathy. Clinical spectrum and treatment. Circulation. 1995 Oct 1;92:1680-92.

17. Drake CG. Experience in surgery of vertebrobasilar aneurysms: London, Ontario experience on 1767 patients. Springer Publishing March 1996.

18. Barnett HJM, Taylor DW, Eliasziw M, et al for the North American Symptomatic Carotid Endarterectomy Trial Collaborators (NASCET). Benefit of carotid endarterectomy in patients with symptomatic moderate or severe stenosis. N Engl J Med. 1998; 339:1415-25.

19. European Carotid Surgery Trialists' Collaborative Group. Endarterectomy for moderate symptomatic carotid stenosis: interim results from the MRC European Carotid Surgery trial. Lancet. 1996;347:1591-3.

20. Morgenstern L, Fox AJ, Sharpe BL, Eliasziw M, Barnett HJM, Grotta $\mathbf{J}$ for the NASCET Group: the risks and benefits of carotid endarterectomy in patients with near occlusion of the carotid artery. Neurology. 1997;48:911-15.

21. Barnett HJM, Peerless SJ, Kaufmann JCE. "Stump" of internal carotid artery - a source for further cerebral embolic ischemia. Stroke. 1978;9:448-56.

22. Barnett HJM, Boughner DR, Taylor W, Cooper PE, Kostuk WJ, Nichol PE. Further evidence relating mitral valve prolapse to cerebral ischemic events. N Engl J Med. 1980;302:139-44.

23. Avierinos JF, Brown RD, Foley DA, et al. Cerebral ischemic events after diagnosis of mitral valve prolapse: a community-based study of incidence and predictive factors. Stroke. 2003;34: 1339-44.

24. Buchan A, Balami JS, Arba F. Chapter 16. Prevention, treatment \& rehabilitation; treatment of acute stroke: medical and interventional therapy. In Spence, David \& Barnett, HJM, editors. McGraw Hill; Toronto (2012);214-62.

25. Mohr JP, Caplan LR, Melski JW, Goldstein RJ, Duncan GW, Kistler JP, Pessin MS, Bleich HL.The Harvard Cooperative Stroke Registry: a prospective registry. Neurology. 1978 Aug;28(8): 754-62.

26. Barnett HJM, Gunton RW, Eliasziw M, et al for the North American Symptomatic Carotid Endarterectomy Trial (NASCET) Group. The causes and severity of ischemic stroke in patients with internal carotid artery stenosis. JAMA. 2000;283(11):1429-36.

27. Chabriat H, Joutel A, Dichgans M, Tournier-Lasserve E, Bousser M-G. CADASIL. Lancet Neurol. 2009;8(7):643-53. 